\title{
Participação das crianças em intervenção precoce: representações sociais de técnicas e famílias
}

\author{
Manuela Sofia Fuste Lapa* \\ Catarina Tomás Almeida**
}

\section{Resumo}

O objetivo do presente estudo é o de caracterizar as representaçóes sociais de técnicas e de famílias sobre as crianças e os seus direitos, com especial enfoque na participação em processos de intervenção precoce (IP). Do ponto de vista metodológico, trata-se de uma investigação de natureza qualitativa, centrada num estudo de caso realizado no distrito de Setúbal, em Portugal. Foram aplicados questionários e entrevistas às técnicas de IP e às famílias de modo a possibilitar uma caracterização dos seus discursos. Para analisar os dados, recorremos à categorização e análise dos discursos, que conduziu à elaboração de um texto indutivo e interpretativo, tendo como referência um quadro multidisciplinar que coloca em diálogo a Sociologia da Infância e a Intervenção Precoce. Nos discursos analisados, as crianças são representadas como sujeitos de direitos, nas dimensões de provisão e proteção. Relativamente à dimensão de participação, esta é marcada por obstáculos à sua concretização e promoção, associados a dimensóes como a menoridade, o paternalismo, a (i)maturidade e a(s) deficiência(s). As crianças são vistas a partir do seu ofício de filho/a e como sujeitos de intervenção. É explícito nos discursos das entrevistadas a dificuldade em concretizar a participação das crianças em práticas de IP. Esta investigação procurou, a partir de complementaridades produtivas entre diferentes saberes e perspectivas, centrar-se na dimensão dos direitos de participação das crianças com deficiência ou risco de desenvolvimento. Pretendeu, ainda, contribuir para repensar e aumentar espaços que promovam e garantam efetivamente os direitos das crianças.

Palavras-chave: Educação Especial; Intervenção precoce; Direitos de participação.

\footnotetext{
* Mestre em Ciências da Educação, com especializaçáo em Intervençáo Precoce. Lisboa, Portugal.

** Professora doutora do Instituto Politécnico de Lisboa. Lisboa, Portugal.
} 


\section{Children's participation in early intervention: social representations of practitioners and families}

\section{Abstract}

The objective of this research is to characterize the social representations of practitioners and families about children and their rights with a particular focus on participation in early intervention practices (IP). Methodologically the research is a qualitative one focusing on a case study conducted in the district of Setúbal in Portugal. Surveys and interviews with EI practitioners and families were conducted in order to enable a characterization of their discourses. Data was analysed through discourse categorization and analysis which led to an inductive and interpretive text, taking as reference a multi-disciplinary framework that places the Sociology of Childhood and Early Intervention into dialogue. In the analysed discourses children are represented as subjects of rights in the dimensions of provision and protection. In relation to participation, it is marked by obstacles to its realization and promotion based on the dimensions as a minority, paternalism, to (im)maturity and disability(ies). Children are seen as son/daughter and as subjects of intervention. It is explicit in the interviews the difficulty in implementing children's participation in practices of IP. This research sought to bring a value-added contribution especially for bringing productive complementarities between different knowledge and perspectives and focus on the extent of participatory rights of children's with disabilities or at risk of development. It also intended to contribute to rethinking and increasing opportunities that effectively promote and guarantee children's rights.

Keywords: Special Education; Early intervention; Participatory rights.

\section{Infância, crianças e direito de participação}

Durante séculos, sobretudo devido à sua dependência e fragilidade, as crianças eram vistas a partir da sua negatividade constituinte (SARMENTO, 2005), o que não pode ser desligado do contexto histórico e científico onde estas representaçôes foram geradas. A criança era tratada como um adulto incompetente, sendo entendida, sobretudo, a partir do que não era. Em contrapartida, nos últimos séculos temos assistido a transformaçóes acerca do modo como se encara as crianças e a infância. Estas modificaçôes devem-se, sobretudo, a movimentos que se iniciaram na decáda de 70 do século XX através, por exemplo, do desenvolvimento de alguns campos do saber como a Sociologia da Infância (JAMES \& PROUT, 1990), e teremos que destacar o papel importante que a Convenção sobre os Direitos da Criança (1989) teve neste processo de revolucionar a forma como se olha para a infância, pois, entre outras questôes, defende-se que as crianças devem ser encaradas como atores sociais e a infância como uma categoria social de tipo geracional com direitos.

Quando refletimos acerca da evolução das representaçóes sociais das crianças e da infância, sobressaem as mudanças de como foram surgindo novos mapas e desbravados territórios que atualmente ainda não se encontram consolidados relativamente 
ao estatuto das crianças, ou seja, ao lugar que lhes é atribuído pela sociedade como um cidadão de direitos (PERCY-SMITH \& THOMAS, 2010). Como afirma Castodi, "apesar das inúmeras conquistas advindas dos avanços científicos e tecnológicos, sobretudo no âmbito jurídico que vêm cada vez mais reconhecendo as crianças como sujeitos de direitos" (2011, p.1), esta é uma área que ainda não se conseguiu efetivamente concretizar quer à escala global, quer à escala local, como no caso de Portugal. O país melhorou, sobretudo após a revolução de 25 de abril de 1974, em quase todos os indicadores, com especial destaque para as políticas de protecção das crianças. Não obstante, continuamos a assistir a uma discrepância entre o que está na lei e as práticas sociais. Esta importância afetiva atribuída à infância não teve uma tradução direta no ainda elevado número de crianças colocadas em instituiçóes de acolhimento e na discriminação relativa às crianças com deficiência e incapacidades (PORTUGAL, 2010). Se nos focarmos neste último grupo, verificamos que:

[...] apesar de se ter verificado um grande desenvolvimento sobre estes temas em diferentes países, o conhecimento disponível sobre as deficiências e incapacidades em Portugal é manifestamente lacunar, de origem fundamentalmente experiencial, assistemático e não estruturado, não integrado e de difícil acesso. (CASANOVA, 2008, p. 4).

Podemos então afirmar que, apesar de todas as transformaçóes positivas nas condiçóes de vida das crianças, "persistem os factores de desigualdade social, baseados em condições estruturais e representações sociais, culturais, simbólicas e ideológicas subjacentes à idade/geração" (SARMENTO et al., 2006, p.149).

Uma vez que a participação é o enfoque desta investigação, é importante referir que é necessário apostar na promoção deste direito porque as crianças não são meras espectadoras, mas atores sociais, inclusive aquelas que têm alguma deficiência ou risco de desenvolvimento.

Ao adotar a Convenção sobre os Direitos de Pessoas com Deficiência e protocolo facultativo na 61 a Sessão da Assembleia-Geral das Naçóes Unidas, realizada em 13 de Dezembro de 2006, Portugal aceita estar vinculado juridicamente à obrigação de tratar as pessoas com deficiência como sujeitos de direitos como qualquer outro cidadão. No preâmbulo da Resolução da Assembleia da República n. 56/2009, que aprova a Convenção sobre os Direitos de Pessoas com Deficiência, é reconhecido na alínea "que as crianças com deficiência devem ter pleno gozo de todos os direitos humanos e liberdades fundamentais, em condiçôes de igualdade com as outras crianças e relembrando as obrigaçóes para esse fim assumidas pelos Estados Partes na Convenção sobre os Direitos da Criança" (Diário da República, 2009, p. 4918).

A Convenção sobre os Direitos de Pessoas com Deficiência não cria direitos novos, uma vez que os direitos já são reconhecidos por outros instrumentos das $\mathrm{Na}$ ções Unidas, como é o caso da CDC. Por conseguinte, todas as crianças devem ser ouvidas para que possamos percepcionar a sua forma de olhar e interpretar o mundo e a sua cultura, suscitando a mudança das representaçóes sociais, culturais, simbólicas e ideológicas que tendem em persistir, como referem os autores supracitados. 
O conceito de participação está longe de obter consenso nas diversas esferas, sejam elas científicas ou políticas, apesar de ser um princípio reconhecido pelas organizaçôes internacionais. Dadas as dúvidas e imprecisôes que atravessam os discursos sobre os direitos das crianças acerca do conceito de participaçáo e para não cairmos em ideologias ocas, sem significado e sem sentido, levou-nos a tornar claro o mesmo. Assim, neste artigo opta-se pelo seguinte conceito:

[...] influir diretamente nas decisóes e no processo em que a negociação e a concertação entre adultos e crianças são fundamentais, um processo que possa integrar tanto as divergências como as convergências relativamente aos objectivos pretendidos e que resultam de um processo hibrido. A participaçáo é um processo gradual, mas seguro, que se pretende, pela experiência e pela aprendizagem da participação das crianças seja um valor em si mesmo e um direito fundamental da infância no reforço dos seus valores democráticos. (TOMÁS \& GAMA, 2011, p. 3).

Continuamos numa situação em que o aceitável a nível social e debatido nas mais variadas esferas, desde políticas a científicas, encontra barreiras na sua aplicação prática ao deparar-se com algumas representaçōes ${ }^{1}$ sobre as crianças que continuam a vigorar (TOMÁS, 2011). Apesar de ter havido alteraçóes ao nível do estatuto da infância e nas representaçóes sociais acerca das crianças, não deixam de persistir os fatores que levam a exclusôes derivadas das representaçôes que se encontram associadas à idade, deficiência(s) e (i)maturidade.

O importante é compreender essas representaçôes e discutir posiçóes quer entre os mesmos grupos sociais, quer entre grupos sociais distintos. Do diálogo, da confluência e divergência de pensamentos advêm modificaçóes, é com esta esperança que olhamos para as representaçóes sociais sobre as crianças. As representações e transformaçôes sociais, no campo dos direitos da criança e da sua participação foram surgindo ao longo do tempo, em confluência com pensamentos (re)construídos pela sociedade, mas sáo várias as polêmicas associadas à sua participação, apesar da crescente consciencializaçáo do paradigma da criança como ator social.

O olhar do adulto para a criança não é feito de modo isolado, ele reflete o que se encontra patente na sociedade, fruto de construçóes de imagens elaboradas e partilhadas que envolvem o conhecimento de si e do outro. As condiçóes das crianças, quer materiais, quer simbólicas, quer sociais, são fruto das representaçóes que os adultos delas têm (MARTINS, 2005).

Compreender representaçóes sociais, revindicar transformações dessas representaçóes e, consequentemente, de práticas institucionalizadas baseadas nessas concepçôes implicam uma profunda partilha de conhecimento e do pensamentos entre indivíduos do mesmo grupo social, mas também de grupos sociais distintos, procurando a partir de diversos conhecimentos, inclusive científicos das mais diversas áreas, cruzar informaçóes e dialogar, neste caso específico referimo-nos à Sociologia da Infância e à Intervençáo Precoce para que se possa refletir sobre processos de intervençẫo, sobre práticas e culturas profissionais. Na nossa perspectiva está na altura de encararmos que as crianças sáo: 
[...] Mais do que um ser no mundo, (...) se tornou uma presença no mundo, com o mundo e com os outros. Presença que, reconhecendo a outra presença como um náo-eu se reconhece como si-própria. Presença que se pensa a si mesma, que se sabe presença, que intervém, que transforma, que fala do que faz mas também do que sonha, que constata, compara, avalia, valora, que decide, que rompe. (FREIRE, 2005, p. 20).

\title{
Reflexão em torno dos modelos e práticas de intervenção precoce
}

Segundo a European Agency for Special Needs and Inclusive Education, a Intervenção Precoce (IP)

\begin{abstract}
"é uma área importante quer a nível político quer a nível profissional, no que respeita ao direito das crianças em idades muito precoces e das suas famílias, a receber o apoio de que necessitam. A Intervenção Precoce na Infância tem como objectivo apoiar e fortalecer a criança, a família e os serviços envolvidos. Ajuda, assim, a construir uma sociedade inclusiva e coesa que esteja atenta aos direitos das crianças e de suas famílias". (2003/2004, p. 4).
\end{abstract}

De forma semelhante ao conceito de participação, o conceito de IP está longe de ser unívoco (PIMENTEL, 1999) e tem evoluído ao longo do tempo, sobretudo fruto de investigaçôes cientificas que têm vindo a ser realizadas, sendo refletido todo este processo, quer no campo teórico, quer no campo das práticas, levando-nos a chegar à concepção atual de IP.

De uma intervenção focada na criança (modelo médico) passamos para uma intervenção focada na família, numa abordagem que envolve a criança que faz parte integrante da família e o meio envolvente (comunidade) - o modelo social (European Agency for Special Needs and Inclusive Education, 2003/2004). Vejamos o quadro 1 que sumariza a evolução ocorrida:

\begin{tabular}{|l|l|l|}
\hline \multicolumn{1}{|c|}{ Indicadores } & \multicolumn{1}{|c|}{ Modelo anterior } & \multicolumn{1}{c|}{ Modelo Atual } \\
\hline Grupos-alvo & $\begin{array}{l}\text { Crianças de 0-3 anos com } \\
\text { deficiência }\end{array}$ & $\begin{array}{l}\text { Crianças de 0-5 anos com } \\
\text { deficiência e/ou outros } \\
\text { fatores de risco e respectivas } \\
\text { famílias }\end{array}$ \\
\hline $\begin{array}{l}\text { Contexto onde ocorre a } \\
\text { intervenção }\end{array}$ & $\begin{array}{l}\text { Centros de estimulação; } \\
\text { centros terapêuticos; } \\
\text { instituiçóes }\end{array}$ & $\begin{array}{l}\text { Contexto natural (creche, } \\
\text { casa, etc.), integrado nas } \\
\text { rotinas. Base comunitária }\end{array}$ \\
\hline Práticas dos profissionais & Programas standard & $\begin{array}{l}\text { Programas específicos, } \\
\text { individualizados }\end{array}$ \\
\hline
\end{tabular}




\begin{tabular}{|l|l|l|}
\hline Papel dos profissionais & $\begin{array}{l}\text { Peritos/decisores. } \\
\text { Dependendo dos saberes } \\
\text { profissionais para resolução } \\
\text { dos problemas, definindo } \\
\text { estes as necessidades das } \\
\text { pessoas }\end{array}$ & Facilitadores \\
\hline Papel das famílias & $\begin{array}{l}\text { Receptoras passivas de } \\
\text { serviços }\end{array}$ & $\begin{array}{l}\text { Participantes ativas/parceiras } \\
\text { dos profissionais/decisoras }\end{array}$ \\
\hline $\begin{array}{l}\text { Objetivos da intervenção } \\
\text { precoce }\end{array}$ & $\begin{array}{l}\text { Desenvolvimento da criança } \\
\text { Prevenção, } \\
\text { compensação(deficiência), } \\
\text { inclusão }\end{array}$ \\
\hline Resultados & $\begin{array}{l}\text { Focados na remediação da } \\
\text { deficiência }\end{array}$ & $\begin{array}{l}\text { Empoderamento/ } \\
\text { capacitaçáo da família }\end{array}$ \\
\hline Trabalho de equipe & $\begin{array}{l}\text { Multi ou interdisciplinar. } \\
\text { Uniserviço }\end{array}$ & $\begin{array}{l}\text { Transdisciplinar e } \\
\text { interserviços (com inclusão } \\
\text { da família) }\end{array}$ \\
\hline $\begin{array}{l}\text { Modelo Conceptual da } \\
\text { intervenção precoce }\end{array}$ & $\begin{array}{l}\text { Centrada na criança e } \\
\text { nos seus déficits. Modelo } \\
\text { médico }\end{array}$ & $\begin{array}{l}\text { Centrada na família, } \\
\text { baseada nas suas forças, } \\
\text { focalizada na relaçáo } \\
\text { ecológica e reflexiva. } \\
\text { Modelo social }\end{array}$ \\
\hline
\end{tabular}

Quadro 1 - Evolução da Intervenção Precoce (adaptado de BOAVIDA \& BORGES, 2003).

Em Portugal, a IP precocemente seguiu um caminho que lhe garantiu um reconhecimento científico, teoricamente individualizado, distanciando-se, gradualmente, da regulamentação inicial ancorada à Educação Especial e Pré-Escolar. Devido a modificaçóes que a sociedade foi sofrendo, assistiu-se ao reconhecimento da necessidade de dar resposta às crianças com deficiência ou risco de desenvolvimento e à necessidade de novas práticas ao seu atendimento em idades precoces. Ao longo dos anos 90, dissiparam-se os projetos de IP, repartidos entre serviços públicos e privados, implicando maiores exigências, quer a nível financeiro, quer legislativo.

Este processo levou a uma tomada de posição por parte dos decisores políticos e culminou, em 1999, com a publicaçáo do Despacho-Conjunto n. 891/99 de 19 de outubro, produzido pelo Ministério da Educação, Ministério da Saúde e Ministério do Trabalho e Segurança Social, constituindo um marco referencial na evolução do modelo de IP.

Posteriormente, o Despacho-Conjunto n. 891/99 foi revogado pelo Decreto -Lei n. 281 de 6 de outubro de 2009, criado com base nos princípios estabelecidos na Convenção dos Direitos da Criança (CDC) e no âmbito do Plano de Ação para Pessoas com Deficiência ou Incapacidade 2006-2009, criando o Sistema Nacional de Intervenção Precoce (SNIPI). ${ }^{2}$ 
Surgem as Equipes Locais de Intervenção (ELI) ${ }^{3}$ do SNIPI, constituídas por profissionais da área da educação, saúde e serviço social e que têm a sua sede em Centros de Saúde, Instituiçôes Particulares de Solidariedade Social que tenham convenção para esse efeito ou em instalaçóes atribuídas pela Comissão de Coordenação Regional de Educação.

O papel da família na prestação de serviços de IP sofreu uma alteração ao ritmo do avanço dos conhecimentos sobre o desenvolvimento da criança, passando a ser "o elemento chave do desenvolvimento da criança e baseia-se na premissa de que todas as famílias têm competências e capacidades que deverão ser reconhecidas e valorizadas" (ALMEIDA, BREIA \& COLÔA, 2004, p. 47).

Atualmente em IP o modelo centrado na família é o recomendado, sendo esta considerada como elemento integrante da equipe, e a transdisciplinaridade é a prática sugerida devido à abordagem holística, integrando a criança e a família, através da partilha e troca de competências e informaçôes entre profissionais, combatendo desta forma a fragmentação da intervenção (ALMEIDA, 2009).

O panorama histórico da IP em Portugal leva-nos, assim, a um passado recente, onde, de algum modo, se perde de vista a criança, no seio da família da qual faz parte, pois é esta quem é chamada a participar ativamente, enquanto a criança é quase sempre o sujeito intervencionado. Náo dizendo com isto que uma abordagem holística não é fulcral em todo o processo de IP, pelo contrário, o envolvimento parental é insubstituível para que qualquer intervenção obtenha sucesso. Contudo, não parece que seja unicamente para esta panorâmica que remete o Decreto-Lei em vigor ao referir a CDC, um marco histórico a nível simbólico na evolução da representação social da infância e das crianças, considerando-as como indivíduos com direitos e liberdades.

Deste modo, várias questôes se colocam: qual é o posicionamento social da criança nos processos de IP? Como são, ou não, promovidos os direitos de participação da criança em IP que estão contemplados na CDC nos artigos $12^{\circ}$ (opiniáo da criança), $13^{\circ}$ (liberdade de expressão), $14^{\circ}$ (liberdade de pensamento, de consciência e de religião), $15^{\circ}$ (liberdade de associação e de reuniáo), 16º (privacidade, honra e reputação) e $17^{\circ}$ (acesso à informação)?

\section{Percurso metodológico e ético}

No quadro de uma abordagem qualitativa foi desenvolvido um estudo de caso em Portugal que envolve dois conselhos pertencentes ao distrito de Setúbal, de 2012 a 2013. É transversal a toda a investigação uma abordagem ética e deontológica situada (ALDERSON \& MORROW, 2004; MAXWELL, 2006; FERNANDES, 2009; FERREIRA, 2010; TOMÁS, 2011).

A metodologia utilizada nesta pesquisa tem como base a questão de partida: Quais são as representaçôes sociais das técnicas e das famílias relativamente ao direito de participação das crianças em intervenção precoce?

A partir desta questão, duas dimensôes de análise foram delineadas: (i) as representaçóes sociais das técnicas que fazem parte de uma equipa de intervenção 
precoce formalmente instituída; técnicas de serviço público e privado que apoiam crianças com planos de intervenção precoce; (ii) as representaçôes sociais das famílias acompanhadas pelas técnicas. Para cada uma das dimensôes foram elaboradas um conjunto de subquestóes.

Apesar desta investigação se assumir como uma pesquisa qualitativa, recolheram-se informaçóes de natureza quantitativa, nomeadamente alguns dados sociodemográficos para podermos compreender melhor a realidade estudada.

$\mathrm{Na}$ recolha de dados foram aplicados questionários, tendo sido entregues 20 às técnicas e devolvidos 18 (90\%), e 50 às famílias, tendo sido devolvidos 24 (48\%). Foram realizadas, ainda, 4 entrevistas semiestruturadas "dado que proporciona uma oportunidade para estudar, de forma mais ou menos aprofundada, um determinado aspecto de um problema em pouco tempo" (BELL, 2008, p. 23).

\section{Caracterização do contexto e dos participantes}

Relativamente ao contexto, a Equipa Local de Intervenção (ELI) tem sede na Cooperativa para a Educação do Cidadáo Inadaptado da Margem Sul do Tejo, envolvendo o conselho $\mathrm{X}^{4}$ e o conselho $\mathrm{Y}^{5}$, pertencentes ao distrito de Setúbal. É constituída por elementos de três Ministérios: Trabalho e da Solidariedade Social ${ }^{6}$, Educação ${ }^{7}$ e Saúde 8 .

As profissionais acompanham 69 casos (média mensal), têm 17 em vigilância, 6 em triagem e 5 novas referenciaçôes aguardarem avaliação.

No que se refere à caracterização das participantes, são 18 técnicas e 24 famílias. Relativamente às características socioprofissionais das técnicas, a maioria têm idade entre os 30-39 anos (55\%), têm como habilitaçôes literárias licenciatura (78\%), com tempos de serviço superiores ou iguais a 13 anos (45\%), exercem atividade profissional em instituiçóes públicas (50\%), tendo como profissão a docência (33\%). Relativamente ao seu nível de participação em IP, são membros da ELI (44\%) e o tempo de acompanhamento das crianças pela ELI varia entre 3-6 anos (44\%).

No que se reporta às características socioprofissionais das famílias inquiridas, estas têm, na maioria, idade entre os 30-39 anos (mães - 71\%, pais - 54\%), o estado civil de $46 \%$ dos casais é casado e têm como habilitaçóes literárias o $12^{\circ}$ ano (mães $50 \%$, pais - 33\%). No que se refere à sua situação profissional, a maioria das mães encontram-se empregadas (63\%), já os pais não sabem ou não respondem (46\%), sendo que o setor profissional dominante é o setor terciário (mães - 75\%, pais - 63\%). O agregado familiar é composto, na maioria, por três elementos (54\%). A maioria das crianças acompanhadas é filho(a) único(a), (63\%), e as famílias são, na sua maioria, nucleares $(75 \%)$. As famílias recebem apoio social (50\%), nomeadamente bonificação por deficiência e abono. As crianças acompanhadas pela ELI, na sua maioria, frequentam um contexto institucional (83\%), sendo que $80 \%$ frequentam a valência de jardim-de-infância. O acompanhamento das crianças pela ELI, na maioria dos casos, iniciou-se através da indicação de algum elemento relacionado com o setor da saúde (54\%). O tempo de acompanhamento da criança pela ELI é variável (desde 3 meses a crianças acompanhadas há 3 anos). 


\section{Conversas polifônicas: representações sociais de técnicas e famílias sobre os direitos de participação das crianças em IP}

Com vista a darem pistas de respostas aos questionamentos das investigadoras, vários caminhos foram passíveis de serem considerados após a análise e interpretação da informação recolhida.

Relativamente às representações sociais das técnicas, estas afirmam conhecer a CDC, de modo geral, a partir de uma diversidade de formas. É defendido que a ausência do conhecimento aprofundado e crítico da CDC é um dos obstáculos à participação das crianças (TOMÁS, 2007). Defendem que nas suas práticas os direitos são considerados, quer nas suas interações com as crianças, quer com as famílias de modo implícito, embora salvaguardam situações claras em que são abordados diretamente. Salientam, ainda, a importância que atribuem à dimensão individual da família e da criança, bem como às práticas individualizadas, realizadas em contexto natural integradas nas suas rotinas. O fato de se tratar de famílias e crianças acompanhadas pela IP por si só aponta para crianças com desenvolvimento atípico ou em risco de desenvolvimento, que têm direitos como quaisquer outras crianças ou famílias. Talvez aqui a deficiência ocupe um lugar central na análise dada(s) a (s) vulnerabilidadede(s) (epistemológica, social, econômica e política) e marginalização destas crianças e famílias que inibem ou dificultam a sua participação.

Salientam várias razôes para a promoção e garantia dos direitos da criança: direitos facilitadores de desenvolvimento e promotores de respeito. No entanto, os direitos são considerados em função dos adultos, centrados na sua ação com as famílias, nos direitos de proteção e provisão. Destacando-se nas suas vozes estes direitos quando referem o acesso a vários serviços: saúde, educação família, sobrevivência e liberdade.

Não obstante, os direitos de participação não aparecem nos seus discursos, apenas quando questionadas sobre os mesmos, o que significam, estes surgem através de múltiplas conceçôes, remetidos para o patamar da opinião/expressão, igualdade de oportunidades, respeito pelas necessidades da criança, levando para o sentido plural de participação (SÁ, 2002). Referenciam a idade, (i)maturidade, deficiência(s) e/ou (in)capacidades da criança como obstáculos à sua concretização em IP.

Relativamente ao modelo de intervenção adotado é defendido o modelo centrado na família, sendo considerado o mais adequado.

A abordagem de trabalho em equipe é feita de modo transdisciplinar, e a família, nos discursos das técnicas, assume um papel de participaçáo ativa ao longo de toda a intervenção, não referindo a participação da criança, levando a considerar que, durante o processo, a sua participação não é tida em conta, sendo vista como sujeito intervencionado, tornando-se quase que invisível, apesar de termos assistido, num passado recente, a uma mudança da visão dos adultos, fruto de várias investigaçóes (AMBERT, 1996; JENKS, 1992; JAMES \& PROUT, 1990; QVORTRUP, 1995). 
A criança é encarada pelos seus discursos a partir da perspetiva do seu desenvolvimento e do seu ofício de filho/a, não como um sujeito de direitos, sendo outro obstáculo à concretização do exercício do seu direito em participar, o que vai contra um princípio fundamental de um dos documentos que serviu de âncora na criação do Decreto-lei 281/2009 que legisla a IP - a CDC.

Este grupo de técnicas partilhou e expressou muitos pensamentos, crenças e significados comuns atribuídos à imagem de criança, sendo considerado que estes relatos têm um papel latente nas suas práticas, relativo à participação das crianças neste contexto. Embora considerem que a criança participa, tal não acontece, pois a verdadeira participação implica o reconhecimento do direito a participar, capacidades para exercer esse direito e meios/espaços adequados para que seja possível a sua concretização (TOMÁS, 2011).

Relativamente à articulação entre os direitos da criança e da família não são claramente referidos os direitos da família, alguns dos direitos das crianças são subentendidos nos seus discursos, mesmo quando esta manifesta que não quer ser alvo de intervenção por parte das técnicas, não obstante, a tensão existente entre estas duas instituiçóes sociais também não é explicitamente mencionada.

Neste sentido, podemos dizer que há alguma articulação entre os direitos das crianças e das famílias, apenas no direito de participação essa articulação aparenta não ser tâo visível, pois participar é tomar parte de processos decisórios em que estamos envolvidos, de modo voluntário, responsável e que pretendemos influenciar ou dar o nosso contributo (DELGADO, 2006).

No que se refere às representaçôes sociais das famílias, tal como as técnicas afirmam conhecer de modo superficial a CDC, a partir de formas diversas, sendo considerado por estas que os seus direitos e dos seus filhos são salvaguardados pela ELI.

Relativamente ao direito de participação, os poucos conhecimentos que têm da CDC podem influenciar as formas como encaram o direito de participação, achamno importante, mas na prática pelos seus discursos a sua vontade enquanto adultos prevalece às da criança. Nos seus discursos, apontam como barreiras à participação infantil a pouca idade, não sabem o que é melhor para elas, cabendo aos pais esse papel, encontrando-se as representaçóes sociais da família associadas ao paternalismo.

As suas representações que têm acerca deste direito são diversas, talvez a " diversidade é talvez a palavra-chave para compreender os diálogos (...): diversidade de olhares, diversidade de vozes, diversidade de culturas (e subculturas) em presença" (SILVA et al, 1996, p. 179).

Nas suas vozes a família é um agente interventivo, ativo e participativo ao longo de todo o processo de IP, ao contrário das crianças. 


\section{Conclusão}

A investigação realizada permite-nos identificar alguns paradoxos e desajustes que continuam a existir atualmente no que concerne aos direitos da criança, referidos quer na Convenção sobre os Direitos de Pessoas com Deficiência, quer na CDC, existindo uma lacuna entre a teoria e a prática, sobretudo no que se refere aos direitos de participação das crianças em IP.

Consideram a criança com deficiência ou risco de desenvolvimento sujeitos de um discurso de direitos, mais do que sujeitos de direitos.

Assistimos a práticas de baixa intensidade, no que se refere à participação das crianças no decorrer dos processos de IP, embora seja transversal nos discursos recolhidos das técnicas e das famílias a importância da sua participação, mas a sua difícil concretização neste contexto.

Nos seus discursos são revelados conceitos de infância e direitos de participação da criança herdados da modernidade, baseados em conceçóes que tendem em persistir e reproduzir-se. Os seus discursos não revelam distinção entre criança com deficiência ou risco de desenvolvimento e criança com desenvolvimento típico. Consideram importante a participação da criança ao longo de todo o processo de IP, mas efetivamente não se realiza, considerando que o adulto sabe o que é melhor para a criança.

As crianças são representadas enquanto sujeitos de direitos na dimensão da proteção e da provisão, já a dimensão da participação é marcada pela "eloquência das ausências" (SÁ, 2002, p.133), sendo elencadas barreiras para a sua não promoção, tais como a menoridade, (i)maturidade, paternalismo e a(s) incapacidade(s) ou deficiência(s). Isto ajuda a perceber as relaçóes de poder entre adultos e crianças, que ocorrem de cima para baixo e não de modo horizontal.

Ligada a uma prática de um modelo de IP centrado na família, sendo as crianças encaradas como parte integrante da mesma e inseridas na comunidade, percecionadas através do seu desenvolvimento, do seu ofício de filho/filha e sujeitos de intervenção, invisíveis em todo o processo, torna-se perentório a necessidade de promover e garantir a participação das mesmas em IP, de modo a romper com paradoxos que marcam as crianças e a infância, de modo a assegurar a sua participação como sujeitos de direitos reclamado pela CDC, um dos documentos base da criação do Decreto-Lei 281/2009 que legisla a IP.

Através destes resultados torna-se evidente o desafio social e acadêmico que se encontra perante a sociedade. É fundamental a desancoragem da visáo partilhada da criança, de infância e do seu direito de participação em IP, implicando, deste modo, estudos teóricos que se debrucem sobre estas questóes que visam uma articulação interdisciplinar. De modo a que vários profissionais e múltiplas áreas de saber se possam cruzar e aumentar espaços de debate que conduzam à modificaçôes no modo de olhar para esta categoria social para que a promoção e garantia permanente do direito de participação das crianças com deficiência ou risco de desenvolvimento não passe de uma quimera. 


\section{Referências}

ALDERSON, P. \& MORROW, V. Ethics, social research and consulting with children and young people. London: Barnardo's, 2004.

ALMEIDA, I. C. Estudos sobre a intervençáo precoce em Portugal: ideias dos especialistas, dos profissionais e das famílias. Lisboa: Coleção Informar - INR, 2009.

ALMEIDA, I.C; BREIA, G.; COLÔA, J. Conceitos e práticas em intervenção precoce. Lisboa: Direçấo geral de inovaçấo e desenvolvimento curricular, direção de serviços da educaçáo especial e do apoio socioeducativo, 2004.

AMBERT, A. M. Sociology of sociology: the place of children in north american sociology. In: ADLER, P. A. \& ADLER, P. (Eds.), Sociological studies of child development, v. 1, 1996, p. 11-31.

BELL, J. Como realizar um projeto de investigaçáo. Lisboa: Gradiva, 2008.

BOAVIDA, J. E.; BORGES, L. Intervenção precoce em desenvolvimento. Saúde Infantil, v. 25, n. 3, p. 23-34, 2003.

CASANOVA, J. Pessoas com deficiências e incapacidades: um inquérito nacional. Artigo apresentado no $4^{\circ}$ Congresso Português de Sociologia. Mundos sociais: saberes e práticas, Lisboa, Faculdade de Ciências Sociais e Humanas da Universidade Nova de Lisboa, jun., 2008.

CASTODI, G. Cosmopolitismo infantil: qual o lugar social das crianças na contemporaneidade? Disponível em: <http://www.periodicos.ufsc.br/index.php/zeroseis/article/view/1980-4512.2011n23p33/17645>. Acesso em: 2 maio, 2012.

DELGADO, P. Os direitos da criança - da participação à responsabilidade. O sistema de proteção e educação das crianças e jovens. Porto: Profediçōes, 2006.

FERNANDES, N. Infância, direitos e participação. Representaçôes, práticas e poderes. Porto: Ediçôes Afrontamento, 2009.

FERREIRA, M. “- Ela é nossa prisioneira!” - Questôes teóricas, epistemológicas e ético-metodológicas a propósito dos processos de obtenção da permissão das crianças pequenas numa pesquisa etnográfica. Revista Reflexão e Acçáo, v. 18, n. 2, 2010, p. 151-182.

JAMES, A. \& PROUT, A. Constructing and reconstructing childhood: contemporany issues in the sociological study of childhood. London: Falmer Press, 1990.

JENKS, C. The sociology of childhood-essential readings. Hampshire: Gregg revivals, 1992.

JODELET, D. Representaçôes sociais: um domínio em expansão. In: JODELET, D. (Org.). As representaçóes sociais. Rio de Janeiro: EdUERJ, 2001, p. 17-44.

MARTINS, P. Das dificuldades (dos) menores aos problemas (dos) maiores: elementos de análise das representaçôes sociais sobre as crianças em risco. Disponível em: <http://hdl.handle.net/1822/3602>. Acesso em: 20 jun. 2013.

MAXWELL, J. A. Qualitative research design: an interactive approach. Sage publications applied social research methods series. V.41. Thousand Oaks: Sage, 2005.

PERCY-SMITH, B.; THOMAS, N. A handbook of children and young people's participation: perspectives from theory and practice. Abingdon: Routledge, 2010.

PIMENTEL, J. Reflexốes sobre a avaliação de programas de intervenção precoce. Análise Psicológica, v. 17, n. 1, 1999, p. 143-152.

PORTUGAL, S. et al. Estudo de avaliaçáo do impacto dos custos financeiros e sociais da deficiência - relatório final. Disponível em: <http://www.ces.uc.pt/myces/UserFiles/livros/1097_impactocustos\%20(2).pdf>. Acesso em: 19 jun. 2013.

PORTUGAL. Ministério da Educação, Ministério da Saúde e Ministério do Trabalho e Segurança Social. Decreto n. 281 de 2009. Lisboa, DR, 2009.

Resoluçáo da Assembleia da República n. 56/2009. Lisboa, DR, 2009.

. Ministério da Educação, Ministério da Saúde e Ministério do Trabalho e Segurança Social. Despacho-

Conjunto n. 891 de 1999. Lisboa, DR, 1999. 
QVORTRUP, J. Childhood in Europe: A new field of research. In CHISHOLM, L. et al. (Orgs.). Growing up in Europe: contempornry horizons in childhood and youth studies. Berlin/New York: Walter de Gruyter \& Co, 1995, p. 17-21.

SÁ, V. A (não) participaçáo dos pais na escola: a eloquência das ausências. Disponível em: <http://repositorium.sdum.uminho.pt/handle/1822/16558>. Acesso em: 5 jul. 2013.

SARMENTO, M. J. As culturas da infância nas encruzilhadas da $2^{a}$ modernidade. In: SARMENTO, M. J.; CERISARA, A. B. (Org.). Crianças e miúdos. Perspectivas sociopedagógicas da infância e educaçáo. Porto: Asa Editores, 2004, p. 9-34.

Sarmento, M. Geraçôes e alteridade: interrogaçôes a partir da sociologia da infância. Revista Educação \& Sociedade, v. 26, n. 91, p. 361-378, 2005.

SARMENTO, M. et al. Participação social e cidadania ativa das crianças. In RODRIGUES, D. (Org.). Inclusáo e Educaçáo. Doze olhares sobre a educaçáo inclusiva. Sáo Paulo: Summus Editorial, 2006.

SILVA, P.; VIEIRA, R.; ROCHA, C. Diálogos sobre o vivido. A Relação Escola-Família. Educaçáo, Sociedade \& Culturas, n. 6, 1996, p. 141-198.

TOMÁS, C. Participação não tem idade. Participação das crianças e cidadania da infância. Contexto e Educaçáo, Unijuí, v. 22, n. 78, p. 45-68, 2007.

Há muitos mundos no mundo... cosmopolitismo, participaçáo e direitos da criança. Porto: Ediçóes Afrontamento, 2011.

TOMÁS, C.; GAMA, A. Cultura de (não) participação das crianças em contexto escolar. Educação, territórios e (des)igualdades. Artigo apresentado no $2^{\circ}$ Encontro de Sociologia da Educação, Porto, Faculdade de Letras da Universidade do Porto, jan. 2011.

\section{Notas}

${ }^{1}$ Segundo Jodelet "as representaçóes sociais indicam a existência de um pensamento social que resultou das experiências, das crenças e das trocas de informaçóes ocorridas na vida cotidiana dos seres humanos. Em outras palavras, são construçóes mentais que surgem de uma necessidade e ajudam a orientar a conduta no dia-a-dia, sendo verdadeiras teorias do senso comum" (2001, p. 22).

${ }^{2} \mathrm{O}$ SNIPI "consiste num conjunto organizado de entidades institucionais e de natureza familiar, com vista a garantir condiçóes de desenvolvimento das crianças com funçóes ou estruturas do corpo que limitam o crescimento pessoal, social, e a sua participação nas atividades típicas para a idade, bem como das crianças com risco grave de atraso de desenvolvimento" (Diário da República, 2009, p. 7298) e tem como objetivos: assegurar às crianças a proteção dos seus direitos e o seu desenvolvimento, detectar e sinalizar, intervir após detecção, apoiar as famílias e envolver a comunidade.

${ }^{3}$ As equipes locais de intervençáo do SNIPI desenvolvem a sua atividade a nível municipal, podendo reunir mais do que um município ou dissociar-se por freguesias. As suas competências são: "a) Identificar as crianças e famílias imediatamente elegíveis para o SNIPI; b) Assegurar a vigilância às crianças e famílias que, embora não imediatamente elegíveis, requerem avaliação periódica, devido à natureza dos seus fatores de risco e probabilidades de evolução; c) Encaminhar crianças e famílias não elegíveis, mas carenciadas de apoio social; d) Elaborar e executar o PIIP em função do diagnóstico da situação; e) Identificar necessidades e recursos das comunidades da sua área de intervenção, dinamizando redes formais e informais de apoio social; f) Articular, sempre que se justifique, com as comissóes de protecção de crianças e jovens e com os núcleos da ação de saúde de crianças e jovens em risco ou outras entidades com atividade na área da protecçâo infantil; g) Assegurar, para cada criança, processos de transiçáo adequados para outros programas, serviços ou contextos educativos; h) Articular com os docentes das creches e jardins - de - infância em que se encontrem colocadas as crianças integradas em IPI" (Diário da República, 2009, p. 7300).

${ }^{4}$ É territorialmente constituído por duas subáreas: a zona Este, que compreende três freguesias e a zona Oeste, composta por cinco freguesias. É sede de um município com 348,09 km² de área e 51222 habitantes (2011). Dados obtidos através do site da Câmara Municipal [Município] e Infopédia. Não aparecerá o link de ligação a nenhuma das páginas consultadas de forma a garantir o anonimato da Equipa Local de Intervençáo Precoce e das famílias.

${ }^{5}$ Tem uma área de aproximadamente $128,5 \mathrm{~km} 2$, é composto por três freguesias, registando, de acordo com os Censos de 2011, 17.565 habitantes. Dados retirados do site da Câmara Municipal [Município] Y, Wikipédia e Infopédia. Não aparecerá o link de ligaçáo a nenhuma das páginas consultadas, pois é de nossa convicção que a equipa local de intervençáo precoce e suas famílias não consigam ser localizadas. 
${ }^{6}$ Uma Técnica de Educação Especial e de Reabilitação (100\%), uma Técnica do Serviço Social (100\%) e uma Psicóloga (100\%) que estáo afetas à instituição que serve de sede onde se encontra a ELI. Dados fornecidos pelas coordenadoras da ELI.

${ }^{7}$ Duas Docentes de Educação Especial (100\%) e uma Educadora de Infância (100\%). que estáo afetas à instituição que serve de sede onde se encontra a ELI. Dados fornecidos pelas coordenadoras da ELI.

${ }^{8}$ Uma Terapeuta da Fala (40\%), uma Pediatra (10\%) e uma Enfermeira (10\%). Dados fornecidos pelas coordenadoras da ELI.

\section{Correspondência}

Manuela Sofia Fuste Lapa - Rua D. Inês de Castro, n. 1, Esq., 2870-414, Montijo - Portugal.

E-mail: manuelaslapa@gmail.com - ctomas@eselx.ipl.pt

Recebido em 09 de setembro de 2014

Aprovado em 16 de dezembro de 2014 